\title{
Pursed-lips breathing for improved oxygenation at altitude
}

\author{
Martin Burtscher
}

Received: 15 December 2008 / Accepted: 15 December 2008/Published online: 6 February 2009

(C) Springer-Verlag 2009

Pursed-lips breathing (PLB) has repeatedly been shown to improve gas exchange with increased arterial oxygenation and saturation $\left(\mathrm{SaO}_{2}\right)$ and decreased arterial carbon dioxide levels mainly by promoting slow and deep breathing pattern [1]. These effects were observed in healthy subjects at low and high altitude and in patients with many forms of pulmonary edema and those with obstructive lung diseases as well. Several mechanisms, e.g. deep breathing, recruitment of terminal airspaces, and changes regarding the work of breathing, the ventilation-perfusion matching, the alveolarcapillary pressure difference, or hemodynamic conditions, may be differently important for the improvement of oxygenation and the relieve of symptoms under various conditions.

In their article in Sleep and Breathing, Tannheimer and colleagues present a case report on the successful therapy of severe acute mountain sickness (AMS) at $4,330 \mathrm{~m}$ by PLB [2], representing an interesting example of simple selftreatment of AMS. Nevertheless, this observation is not surprising because many years ago, Schoene et al. and Larson demonstrated similar results by the application of expiratory positive airway pressure in subjects with high altitude pulmonary edema (HAPE) [3, 4]. Due to the very low resting $\mathrm{SaO}_{2}(62 \%)$ at $4,330 \mathrm{~m}$ of the mountaineer studied by Tannheimer et al., I strongly suggest that this

\footnotetext{
M. Burtscher $(\bowtie)$

Department of Sport Science, Medical Section, University of Innsbruck,

Fürstenweg 185,

6020 Innsbruck, Austria

e-mail: Martin.Burtscher@uibk.ac.at
}

person actually suffered from HAPE. This assumption is also supported by the large $\mathrm{SaO}_{2}$ improvement during PLB. Schoene et al. and Larson also found much more impressive improvements of oxygen saturation in HAPE patients than healthy mountaineers. However, the increase in $\mathrm{SaO}_{2}$ and the expiratory pressure applied $\left(\sim 10 \mathrm{~cm} \mathrm{H}_{2} \mathrm{O}\right)$ in these patients were lower compared to the respective values reported by Tannheimer and colleagues. In fact, increasing expiratory pressures may cause increasing $\mathrm{SaO}_{2}$ values. But, which pressure levels are optimal? Biondi et al. showed that values above $15 \mathrm{~cm} \mathrm{H}_{2} \mathrm{O}$ increased right ventricular afterload and decreased right ventricular contractility [5]. Tannheimer et al. report an extraordinary high expiratory pressure of about $55 \mathrm{~cm} \mathrm{H}_{2} \mathrm{O}$ which could cause hemodynamic complications. Based on our recent observation when applying a continuous positive airway pressure helmet for HAPE treatment, I would suspect that much lower expiratory pressures $\left(\sim 15 \mathrm{~cm} \mathrm{H}_{2} \mathrm{O}\right)$ would have similar effects on the improvement of HAPE symptoms and the increase of arterial oxygenation and saturation as reported by Tannheimer et al. without potential risks arising from very high expiratory pressures [6].

Future studies are necessary to evaluate the effects of various expiratory pressures produced by PLB and to shed more light upon the impact of PLB methods on the complex and interactive physiology of normal and diseased respiratory apparatus.

Although one cannot conclude on the basis of this case report that PLB represents a major treatment option for severe AMS or HAPE, the authors did a good job in conducting and reporting this study which addresses a "real world" medical question stimulating pursuing studies. 


\section{References}

1. Mueller R, Petty T, Filley G (1970) Ventilation and arterial blood gas changes induced by pursed-lips breathing. J Appl Physiol 28:784-789

2. Tannheimer M, Tannheimer S, Thomas A, Engelhardt M, Schmidt R (2008) Auto-PEEP in therapy of AMS in one person at $4330 \mathrm{~m}$. Sleep and Breath. Epub ahead of print. doi:10.1007/s11325-008-0237-z

3. Larson EB (1985) Positive airway pressure for high-altitude pulmonary oedema. Lancet 1(8425):371-373
4. Schoene RB, Roach RC, Hackett PH, Harrison G, Mills WJ (1985) High altitude pulmonary edema and exercise at 4,400 meters on Mount McKinley. Effect of expiratory positive airway pressure. Chest 87:330-333

5. Biondi JW, Schulman DS, Soufer R, Matthay RA, Hines RL, Kay HR, Barash PG (1988) The effect of incremental positive end-expiratory pressure on right ventricular hemodynamics and ejection fraction. Anesth Analg 67:144-151

6. Koch RO, Hinterhuber L, Faulhaber M, Gatterer H, Graupner S, Muenzel K, Burtscher M (2009) A successful therapy of high-altitude pulmonary edema with a CPAP helmet on Lenin Peak. Clin J Sport Med 19:72-73 